\title{
NUMERICAL STUDY OF WATER QUALITY IMPROVEMENT IN A PORT THROUGH A FORCED MIXING SYSTEM
}

\author{
DANIELA MALCANGIO, ANTONIO MELENA, LEONARDO DAMIANI, \\ MATILDA MALI \& ALESSANDRA SAPONIERI \\ Department of Civil, Environmental, Land, Building Engineering and Chemistry, \\ Polytechnic University of Bari, Italy
}

\begin{abstract}
Over the years, the growing development of coastal areas urbanization has led to marine habitat loss and degradation. With the continuous increase in population and industrialization, coastal zones are facing several issues arising from the continued decline in the quality of water and sediments and the rapid deterioration of marine ecosystems. Shipping activities exacerbate such a situation, especially in the vicinity of harbors, which are often affected by stagnant and contaminated waters, containing organic as well as inorganic substances. In Italy, although the environmental legislation does not appropriately consider the port as a water body, specific actions are required in order to properly manage these basins. In this regard, a 3D numerical model is firstly performed to detect the hydrodynamic circulation and the water renewal within a port in the southern Adriatic coast of the Apulian region (South of Italy). Then, some configurations of a possible technical solution, i.e. a pumping system aimed at improving water quality, are modelled. Specifically, the system consists of a pump that draws water from areas with less water exchange and enters it into areas inside the port with lower hydrodynamic circulation. The different results, in terms of (i) number of sinks and sources, and (ii) their location, are compared to obtain the best technical solution that enhances the water renewal and then improves its quality. The study allows readers to identify methods for proper planning and management of such shallow sea areas with low water exchange and thus highly susceptible to accumulation of harmful substances in the water, that are ports.
\end{abstract}

Keywords: ports, water quality, hydrodynamic circulation, port management, water exchange, forced mixing system.

\section{INTRODUCTION}

Harbors are the main interface between cities and the sea. They are often exposed to heavy pressures from human activities and increasingly suffer from environmental degradation risks linked to water and sediment quality [1]-[3]. The multi-source of contamination and other stressors loading on port areas makes them peculiar environmental matrixes, often regulated by specific protocols. Indeed, according to the Italian legislation, ports are considered "artificial water bodies" and pressure on the surrounding coastal areas, thus subjected to complex management quality procedures. There are two main types of deterioration pressures for port areas: internal and external ones. Activities occurred within the port area, such as loading, storage, repair or quay operations, are considered internal pollution factors. Hydrodynamic conditions and morphology are also included in this pressure group, as they tend to enhance and/or to control the fate of contaminants within the port area [4]-[6]. On the other hand, all external processes and factors that, in somehow, can contribute to the worsening of the quality of the port are classified as external pressures (i.e. urban and industrial discharges, atmospheric pollution, development of ports as logistic poles, the rapid urban development along coastal areas, fisheries and aquaculture).

The impact exerted by such factors, either external or internal, can lead to an excess concentration of nutrients and toxic organic contaminants within water columns and bottom 
sediments thus triggering bio-chemical processes such as eutrophication, threating consequently the marine and coastal habitats [5], [6].

The pollution generated within harbors, unlike the rest of the coast, is of major concern due to the tendency of marine contaminants to remain confined within the basin, encouraged by the typical low velocity of marine currents that reduce the water mixing capacity [6] and hinder the dilution of contaminants with the open sea. Trace metals and Persistent Organic Pollutants (POPs) are the two major contaminant categories investigated in the marine surroundings due to their high toxicity and environmental persistence [3]. Some organic pollutants such as polycyclic aromatic hydrocarbons (PAHs) and Polychlorinated biphenyls (PCBs) are also included as priority substances in the Water Framework Directive 2000/60 / EC (EC 2000) [7]. The concern about these contaminants is related with their strong affinity for the suspended solids and finest sediment in which they tend to accumulate and become even more resistant to degradation [6], [8], [9].

The above reported various stressors and the related hazard require adequate management protocols able to guarantee a safety port usability for all stakeholders and end-users. At this regard, it would be useful to foresee measures that can act in parallel with the conventional policies, in order to manage port activities correctly. The application of innovative technological systems aimed at improving the quality of port aquatorium and other preventive measures can be introduced within port management systems.

It is undeniable, nowadays, the utility of numerical simulation codes for research activities in defining innovative technological solutions. From support to design, environmental impact assessment, emergency forecasting and management, the choice of an accurate and reliable numerical model has, over the years, supported the achievement of excellent results [10]-[15]

It is recently reported in literature that hydrodynamic processes controlling water exchange should be considered as leading factors in determining carrying capacity [6]. However, no study has been yet reported for defining possible technical solutions based on port hydrodynamics that can improve the water renewal capacity.

In the present work, the hydrodynamic conditions within the port of Monopoli were investigated in order to explore the circulation process and the water replacement time of internal waters with the external ones. The obtained results are then employed for simulating the capacity of improving hydrodynamic port circulation and reducing the water replacement time, through a pumping system. A three-dimensional numerical modeling software (MIKE 3 FM of DHI) was utilized for the study, widely calibrated and validated in other previous works [6], [12]-[16].

\section{MATERIALS AND METHODS}

\subsection{Study area}

The port of Monopoli is located in the southern Adriatic coast of the Apulian region (South of Italy). It has four bays equipped with berths for mooring vessels (Fig. 1). The surface of the water body extends for approximately $140,000 \mathrm{~m}^{2}$. Despite its modest extend, it is a commercial port, with important touristic and recreational boating and activities, especially close to the old part. Field bathymetric surveys and studies showed an almost constant depth at the center of the harbor, approximately of $9 \mathrm{~m}$. Considering an average water depth of 6 $\mathrm{m}$, it is possible to estimate a total volume of the port water basin of $840,000 \mathrm{~m}^{3}$. 

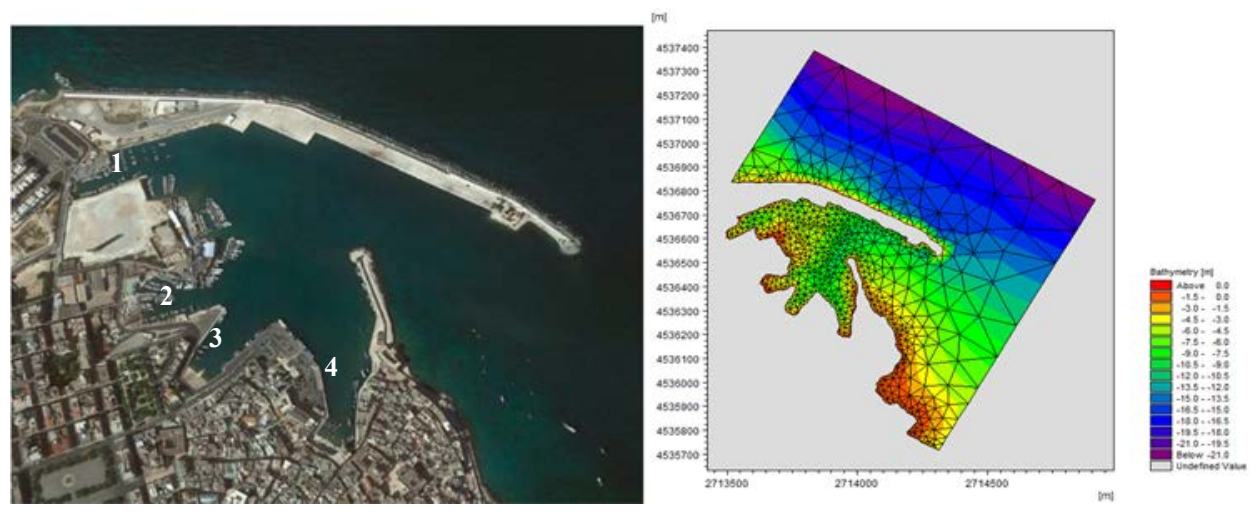

Figure 1: Left: Map of the Monopoli port basin, with the four bays, i.e. (1) Cala Curatori; (2) Cala Fontanelle; (3) Cala Batteria; (4) Old Port. (Source: Google Earth.) Right: Study area bathymetry and model mesh.

Inside the four bays (Fig. 1) the depth decreases, which implies a higher deposition of sediments where the current velocity is lower. Through a sampling carried out in 2011 in the Monopoli port [5], the granulometric characterization of the site under consideration was defined, from which it has been found that the bottom is highly sandy-loam.

Recent studies have shown a considerable concentration of heavy metals in the port, i.e. IPA and PCB [5]. Threats that these substances create for port sediments are also related to the structure of the port, which favors the entry of contaminated fine sediments from the outer zone and hinders their exit from the basin.

\subsection{Numerical modelling}

The three-dimensional model MIKE 3 Flow Model (FM) by DHI (Danish Hydraulic Institute) was used to simulate the flow patterns in the port area and to assist in the evaluation of possible technical solutions able to improve the water quality. The model had been applied in numerous previous studies and tested by means of field measurements [6], [12]-[16].

The MIKE 3 FM is a professional engineering modelling tool for oceanographic, coastal and estuarine applications. The model comprises a hydrostatic hydrodynamic module, various modules for turbulence and incorporates dynamic baroclinic effects from salinity and temperature differences [11]. Thus, the hydrodynamic module numerically solves the classic hydrostatic momentum and continuity equations in order to predict water level changes, circulation and transport driven by winds, waves, tides, river discharge or density forcing.

Along with the HD module, the Transport Module (TR) was used in order to estimate the time needed for the full/partial water exchange within the Monopoli port basin. The TR module simulates the spreading and fate of dissolved or suspended substances in a water body under the influence of the fluid transport and the associated dispersion processes. For this work, a conservative inorganic tracer was considered. The solution of the transport equation, i.e. the conservation equation of a scalar quantity, is closely linked to the solution of the hydrodynamic conditions. The TR module allows to define the initial conditions of varying concentrations in the domain, and returns a mapping of the same over time.

MIKE 3 FM is based on an unstructured mesh and uses a Finite Element solution technique. The meshes are based on linear triangular elements in the horizontal directions 
and generalized sigma coordinates in the vertical. Combined with a semi implicit time marching scheme, this gives an efficient solution procedure. The description of the free surface is based on a generalized wave equation, with implicit formulation of the gravity terms. The model domain was mainly focused on the Monopoli port basin embedding also the outer coastal area, in order to consider possible interactions between inward and outward flows. However, while the port area was discretized by considering a tight mesh, the outer port area was fixed with a larger scale resolution (Fig. 1). In the vertical dimension, the model was set-up using 3 equidistant layers, defined as compressible sigma layers following the oscillations in water level. The deepest depth of the bottom recorded within the port is approximately $11 \mathrm{~m}$.

It was chosen to use a great deal of detail of temporal and spatial discretization, giving importance to the convective flow phenomena. The hydrodynamic simulation was carried out from $21^{\text {st }}$ June 2011 to $1^{\text {st }}$ July 2011, a summer month not characterized by particularly intense weather-marine phenomena that could favor the water renewal. A time step interval of $86400 \mathrm{~s}$ was used without having problems of numerical instability. A proper spatial discretization allowed to use such a high $\Delta \mathrm{t}$. However, the stability of the numerical model is guaranteed by a low CFL number:

$$
\mathrm{CFL}_{H D}=(\sqrt{g h}+|u|) \frac{\Delta t}{\Delta x}+(\sqrt{g h}+|v|) \frac{\Delta t}{\Delta y},
$$

where $h$ is the total water depth, $u$ and $v$ are the velocity components along the $x$ and $y$ direction respectively, and $\Delta t$ is the time step interval. For this study, a critical CFL number of 0.8 was set.

In the present study, it was chosen to use a barotropic approach, because of the modest variations in density. The bed resistance is calculated using a drag law (or partial slip condition) according to the following expression:

$$
\frac{\tau_{b}}{\rho_{0}}=C_{f}\left|u_{b}\right| u_{b}
$$

with $\rho_{0}$ the water density, $C_{f}$ the drag coefficient and $\mathrm{u}_{\mathrm{b}}$ the velocity in lowermost node. The simplification used in the model was to hypothesize a constant $2 \mathrm{~mm}$ roughness on the whole bottom.

The turbulence was modelled following classical expressions according to Smagorinsky model and the log law formulation. The barotropic simulations were performed considering a wind blowing over the modeled area as a principal forcing function, varying in time and constant in domain. The shear stress $\tau$ due to the wind force was formulated as

$$
\tau=C_{D} \rho_{a} W^{2},
$$

where $C_{D}$ is the drag coefficient constantly equal to $0.0026, \rho_{a}$ is the air density of 1.247 $\mathrm{kg} / \mathrm{m}^{3}$ and $W$ is the wind speed at $10 \mathrm{~m}$ above the sea surface. Wind data, together with the upstream boundary conditions, i.e. the water level data, were obtained by the ISPRA (Institute for Environmental Protection and Research) database, considering the station located in the Bari port area (Lat.: $41^{\circ} 08^{\prime}$ 24.74", Long.: $16^{\circ} 51^{\prime}$ 57.72"). From the analysis of wind direction and speed data, it was possible to confirm the presence of a prevailing wind, i.e. with the highest frequency of observation, from the northwest (Fig. 2). Using the principle of geographical transposition, it was hypothesized that anemometric events occur in the Monopoli site with the same direction, intensity and duration of the anemometric event recorded at Bari station.

As additional external forcing function for the barotropic simulation, the Coriolis forcing varying in domain was implemented by the model. 
(a)

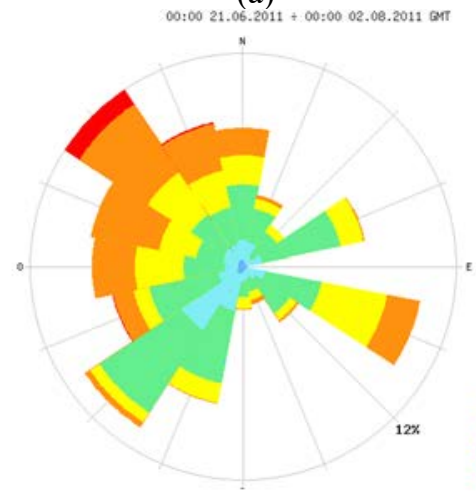

(b)

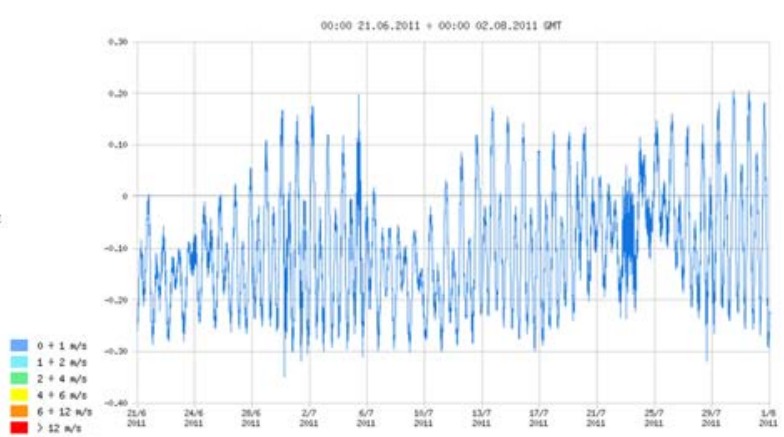

Figure 2: (a) Wind frequency and intensity; (b) Sea water level time series, registered by the Bari airport station from 21st June 2011 to 2nd August 2011.

\section{RESULTS AND DISCUSSION}

\subsection{Hydrodynamics study}

The hydrodynamic simulations have the purpose of first determining the current field due to both sea level and wind variations within the port basin, and subsequently evaluating its water renewal capacity, with reference to a hypothetical tracer of initial concentration defined. By way of example, Fig. 3 shows the circulation patterns obtained for some specific time steps, i.e. the $29^{\text {th }}$ June 2011 (Fig. 3(a)) and $14^{\text {th }}$ July 2011 (Fig. 3(b)), both at midnight. As it could be expected, the currents in Fig. 3 are strongly influenced by the direction of the predominant winds, which involve a completely different water motion that is consistent with them. It should be noted in Fig. 3 the strong influence of the port on coastal hydrodynamics. In fact, a deviation of the velocity vectors carriers near the head of the outer breakwater, as in most of the temporal steps analyzed. Moreover, a strong current, outward in Fig. 3(a) and inward in Fig. 3(b), sprawls thereon. The velocity of the current is always much lower within the port than the outside area, as was expected. Specifically, in the four bays of the port basin, the current velocity is particularly low, resulting in a weak water exchange. Fig. 3 also shows that the flow velocity increases where the bottom is lower (see red circle). This increase in the highlighted zone generates a return current that contributes to the displacement of water masses outside the port in Fig. 3(a) and inside in Fig. 3(b), depending on the meteoclimatic conditions.

It is also interesting to examine the hydrodynamic condition in which currents are quite low throughout the investigated domain. Fig. 4 shows exactly that situation, which was achieved by the simulation at the output time step corresponding to 12th July 2011 at midnight. Fig. 4 indicates the presence of several vortexes. Although sometimes characterized by strong outlying speeds, in the central part the vortexes have very low velocity magnitude and thus can be assumed as indicators for sediment deposition, i.e. stagnation points for the concentration of hypothetical pollutants. 

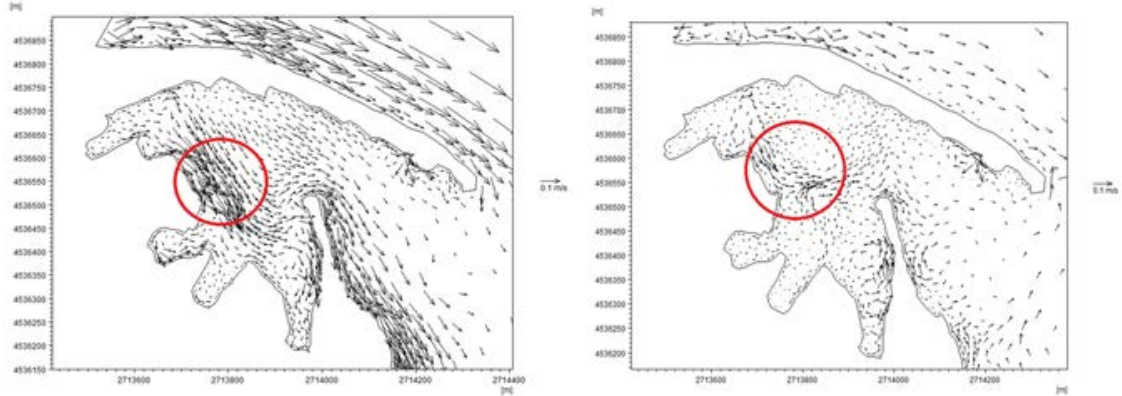

Figure 3: Current velocity on (a) 29th June 2011; (b) 14th July 2011. The red circle indicates the area where the sea bottom is lower.

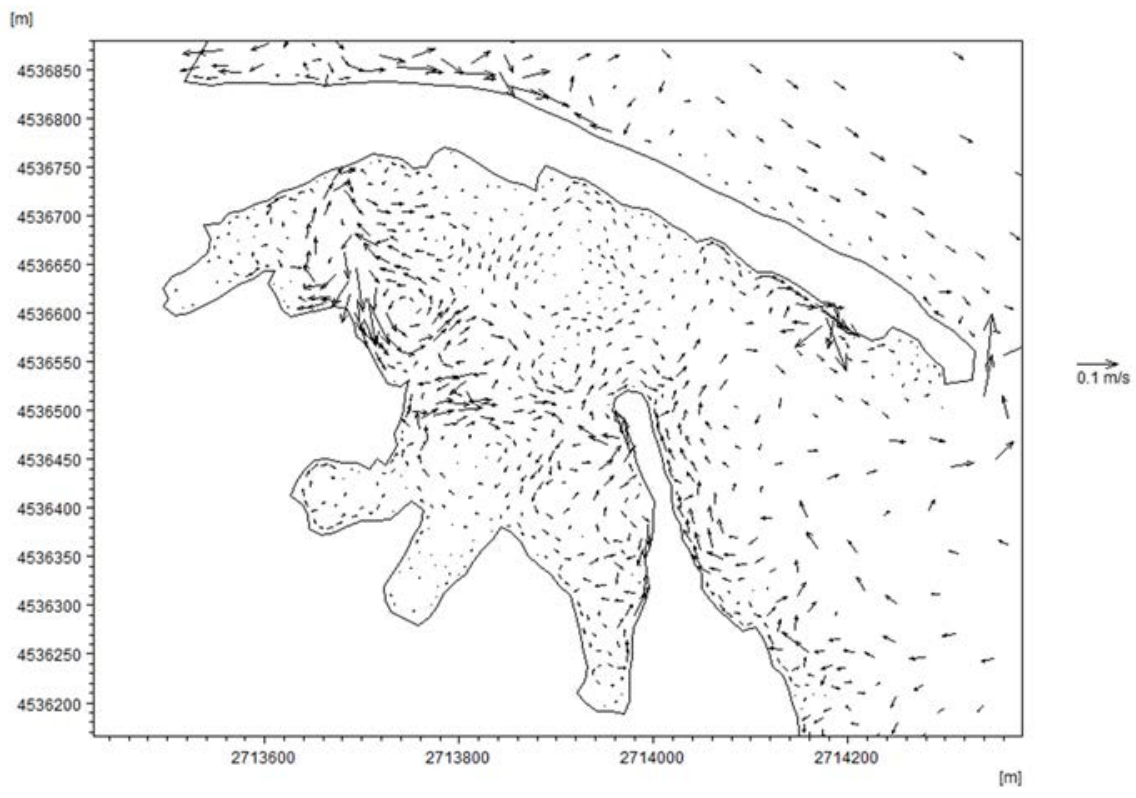

Figure 4: Current velocity on 12th July 2011, with calm of wind meteorological condition.

\subsection{Port water renewal times}

In analytical terms, the water renewal time is defined as the ratio between the volume of water contained in the port and the water flow exchanged at the inlet section of the basin. The assessment of the time required for the full or partial renewal of the waters within the Monopoli port was achieved using the MIKE 3D transport model (TR) coupled with the HD model, following the method described in literature [14], [17]. Then, the hydrodynamic numerical model coupled with the advection-dispersion model simulated the transport of this tracer, i.e. its temporal evolution inside the port basin and its renewal time.

In order to analyse the influence of the initial hydrodynamic conditions on water renewal times, 10 different simulations were performed, referred to specific climate initial conditions 
characterizing different days. The total simulated period is from $22^{\text {nd }}$ June 2011 to $15^{\text {th }}$ July 2011. The duration of each simulation was set equal to 15 days. The initial concentration values of a fictive tracer in the port basin were assigned by means of a regular grid, constituted by $320,0003 \mathrm{D}$ cells ( $5 \mathrm{~m}$ wide, $5 \mathrm{~m}$ large and $2 \mathrm{~m}$ deep). Each cell is characterized by an initial concentration value set to 1 inside the area of interest and 0 outside. For each initial climate condition, the concentration was extrapolated every 24 hours. Results obtained from all simulations were then processed, in order to synthetize results on total as well as partial water renewal times.

Fig. 5 shows the concentration time-dependent reduction rate for each simulation, in correspondence of a representative point of the spatial domain, namely the point where maximum concentration values were expected. The red line represents the mean values of all initial hydrodynamic conditions considered. Results show a reasonable reduction of the concentrations in the examined period. It can be also observed that concentration decay is not constant over the observed period, as confirmed by the curves slopes. In general, the decay increases as the slope increases. Fast concentration decays were observed during days characterized by winds coming from North-West and from South-East, i.e. during $26^{\text {th }} / 27^{\text {th }}$ June and $19^{\text {th }} / 20^{\text {th }}$ July, respectively. In particular, the latter condition increases the sea water motion inside the protected zone from outside, thus favoring the water circulation.

Intense winds with a constant propagation direction enhance the water dilution, by mixing waters of low and high concentration of solutes. For example, the last days of June (run S1 in Fig. 5) were characterized by a constant wind of $8 \mathrm{~m} / \mathrm{s}$, which led to a significant reduction of concentration. Vice-versa, the first days of July (run S8 in Fig. 5), the wind intensity inside the harbor decreased, with a consequent lower efficacy in concentration decay. The analysis of mean values, represented by the red curve in Fig. 5, allows to analyze the general behavior of water circulation inside the port, showing a mean reduction of $80 \%$ in the first 5 days and a final pollutant percentage of $10 \%$ in the worst conditions.

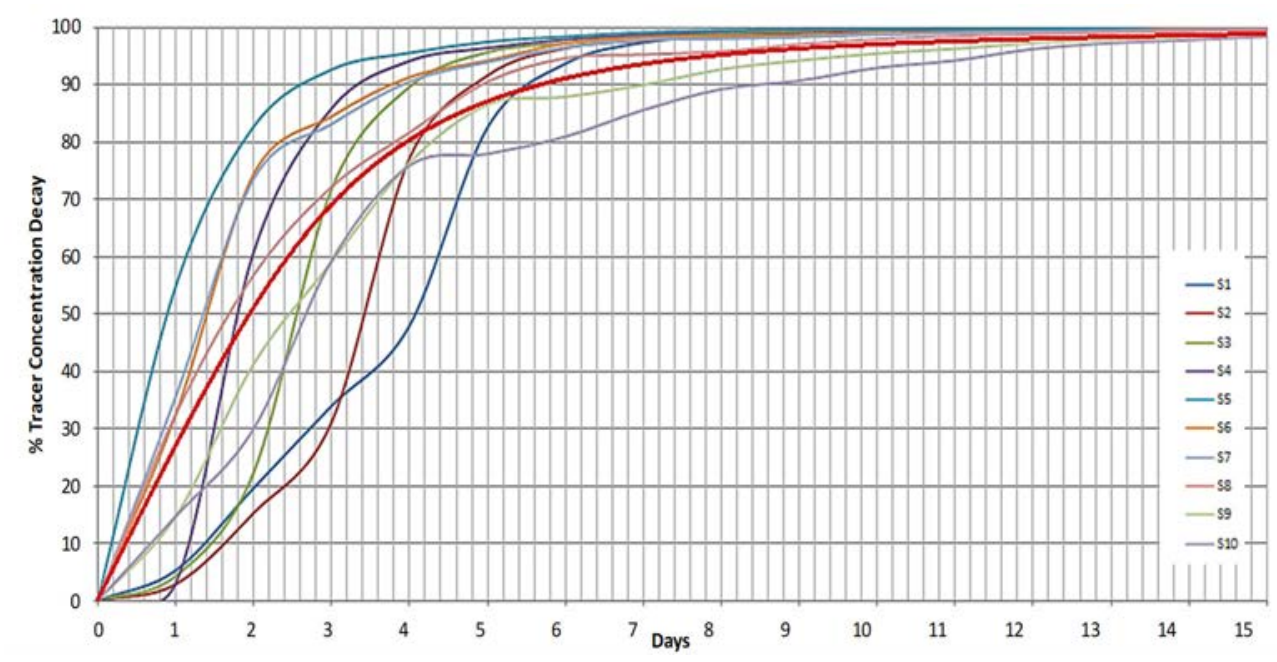

Figure 5: Simulated time-dependant decay of tracer concentration in a representative point of the spatial domain. 


\subsection{Technical solutions}

Operation with a well-designed recirculation system enables water mixing to ensure a reduction in the renewal time and at the same time to avoid stagnation in the closer areas. However, it is necessary to verify that no currents with high velocity are triggered so that they can be considered as a source of danger for boats performing inbound and outbound maneuvers inside the harbor and for mooring boats.

The hydrodynamic study above discussed leads to the result that waters in the Monopoli port with low current velocity typically develop into the inner areas of the 4 harbor inlets, particularly the two central bays, named Cala Batteria and Cala Fontanelle (Fig. 1). Often these bays are also affected by small vortices, especially at highest depths, that cause stagnation in their central part (Fig. 4). Therefore, the different pumping system solutions have always contemplated the two central bays.

The standard source mode was used in the HD module to simulate the technical solution proposed in this study. This option allows to consider the contribution of the momentum equation as well as the mass budget. It is therefore appropriate to specify the flow rate and velocity at which the source or sink pump in or out, respectively.

Fig. 6 shows the five solutions that were implemented by the model to simulate the installation of pumps with source and sink points located inside and/or outside the Monopoli port. In particular, (i) run A (Fig. 6(a)) simulates a pump in Cala Batteria and Cala Fontanelle and two sources in two opposite points inside the port with high current velocity, with the aim of removing the contaminating load from the quiescent areas, (ii) run B (Fig. 6(b)) provides for the installation of a pumping system entirely contained in the two above mentioned inlets, (iii) run C (Fig. 6(c)) considers the source points in Cala Fontanelle and Cala Batterie and the sink points at the center of the harbor, so as to "break" the vortexes that are generated in the central harbor areas, modify the incoming water flow in the bays and pump cleaner water inside them, (iv) run D (Fig. 6(d)) proposes the same solution of run C, with the only difference that the sources' location was reversed with that of the sinks, (v) run E (Fig. 6(e)) proposes one of the most frequently used solutions, albeit often uneconomic, that is to consider the pumping of water from outside the port, which is assumed to be cleaner, within Cala Fontanelle and Cala Batterie. For each of them, the same flow rate of $0.5 \mathrm{~m}^{3} / \mathrm{s}$ in absolute value was considered. A single reference period of 10 days, from $26^{\text {th }}$ June 2011 to $6^{\text {th }}$ July 2011, was simulated.

Investigation of the actual improvement of water quality conditions due to the pumping system was carried out by monitoring, during all simulations, 5 fixed points within the port (Fig. 6(f)), on three depth levels, for a total of 15 monitoring points. The results of tracer concentration analysis over time for the different simulations are shown in Fig. 7. They refer only to the free surface layer, since the results basically do not vary along the depth. As can be seen from Fig. 7, the concentration profile for the different simulations, except for run $\mathrm{D}$, at points t1 (Fig. 7(a)) and t4 (Fig. 7(d)) is very close to that obtained considering natural hydrodynamics without any forced mixing. This is due to the fact that in these points no forced circulation system has been considered, and moreover the waters are not affected by interventions taken in distant places. Runs A and D in Fig. 7 show a deterioration in the quality of port water. With the addition of source points at the center of the harbor, the hydrodynamics has been modified so that the tracer leaving the sources is transported from the sources inside the other two external bays, i.e. Cala Curatori and Old Port. This is certainly due to the non-linearity of the circulation phenomenon. The water masses naturally present in the port basin and artificially pumped in by the forced system originate currents that are governed by different continuity and momentum equations. 

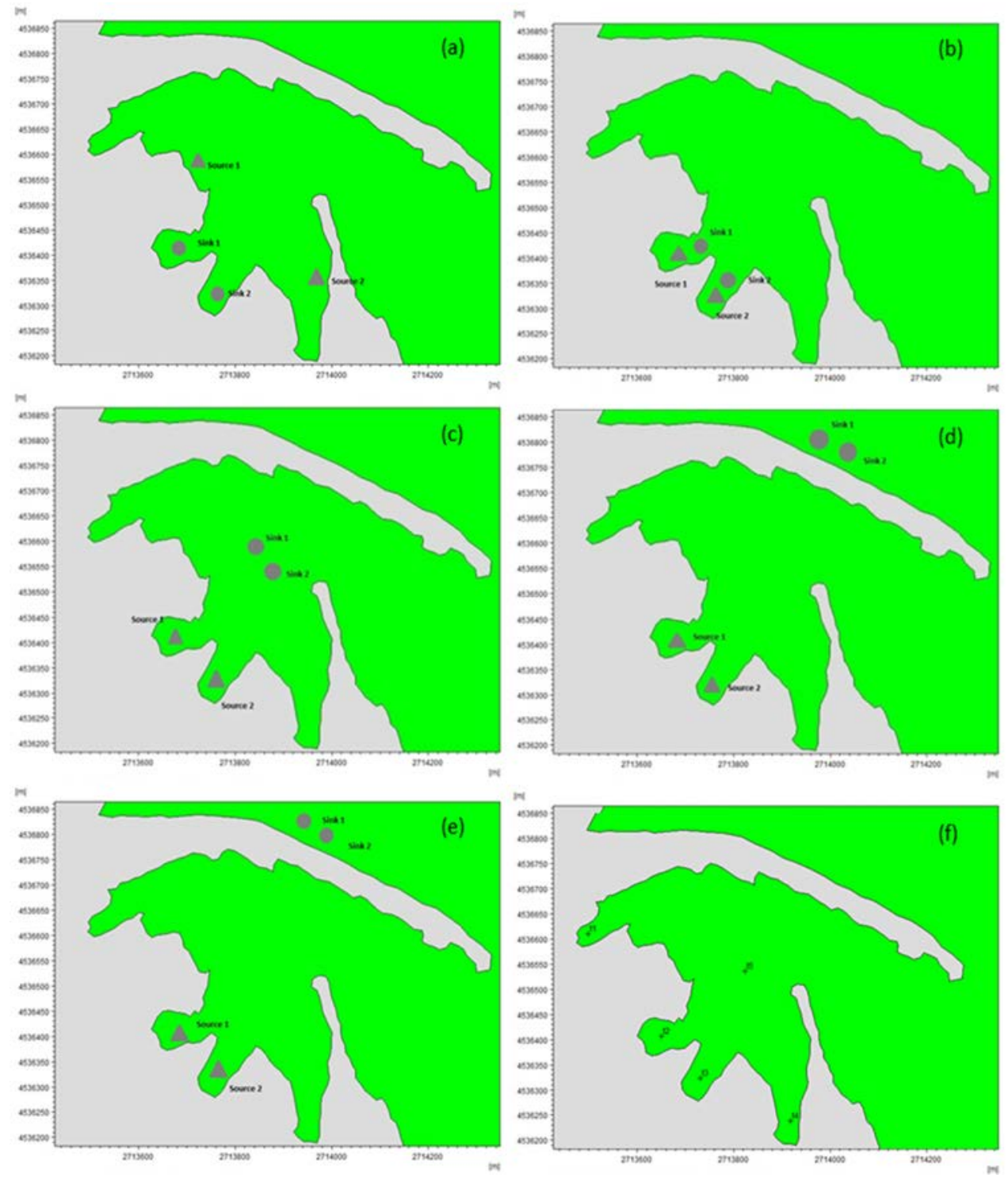

Figure 6: Positioning the source/sink points for (a) run A; (b) run B; (c) run C; (d) run D; (e) run $\mathrm{E}$; (f) points monitored for the analysis of the tracer concentration reduction.

This problem justifies the possibility that contrasting flows may occur in the port basin that could even worsen the water renewal with respect to the natural condition, that is in the absence of pumps. Points t2 (Fig. 7(b)) and t3 (Fig. 7(c)) are those that exhibited the highest tracer concentration values already in the preliminary study phase, in the analysis of hydrodynamic natural conditions. Specifically, in point t3 (Fig. 7(c)) all solutions adopted, with the exception of D1, show an improvement over the natural condition. At point t2 (Fig. 7(b)), on the contrary, run A shows worse results after the third day of observation, with 
a return of contaminated water, taken within the bays, in the same sink points. The points $t 4$ (Fig. 7(d)) and t5 (Fig. 7(e)) show curves almost always above the natural condition, except for the curves related to runs $\mathrm{B}$ and $\mathrm{E}$, that seem to be the best solutions found. The latter, however, presents economic disadvantages. Sink points outside the harbor are difficult to connect to the source points unless using long pipes that can be easily correlated with high load losses. Moreover, the depth of the sink points outside the port contributes to the increase in the overall prevalence of the plant.

In conclusion, it is possible to say that any intervention carried out has impacts that are not always acceptable. For example, while the time to decrease the concentration of a hypothetical tracer at some points is significantly reduced, there are others for which times are lengthening.

\section{CONCLUSION}

A simplified method has been used in this study to evaluate (i) the importance of water renewal in the Monopoli port basin, south Italy, and (ii) a potential technical solution that can favor it.
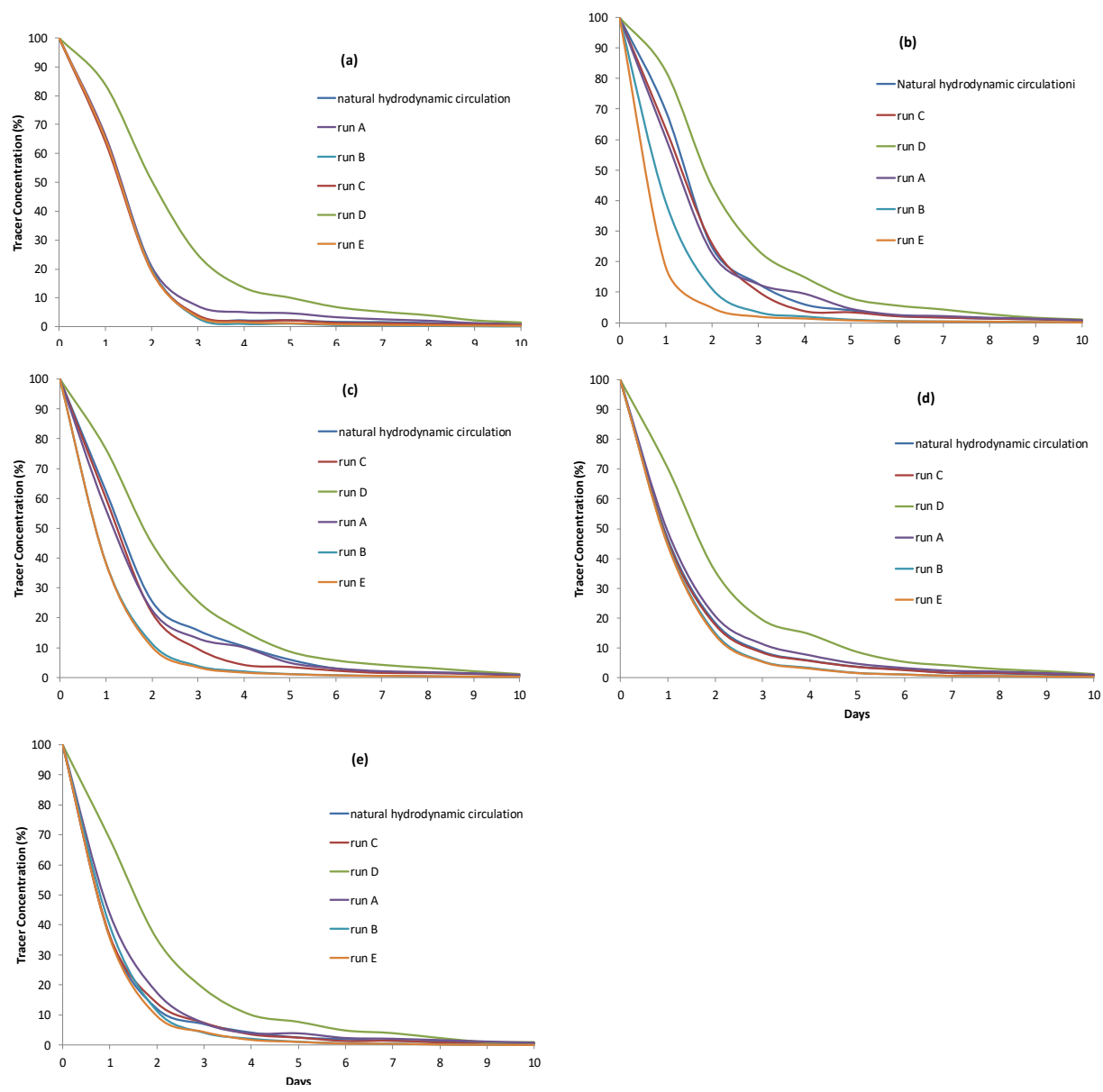

Figure 7: Positioning the source/sink points for (a) run A; (b) run B; (c) run C; (d) run D; (e) run E; (f) points monitored. 
A 3D hydrodynamic model (HD) based on an unstructured flexible mesh has been first used to characterize the flow field in the study area, under different forcing conditions. Then, the HD numerical model has been coupled with the advection-dispersion model in order to evaluate the water exchange time of the port water. A not much windy month has been chosen as precautionary approach for the renewal time valuation. After assessing the natural conditions of the port's water exchange, it was decided to plan an improvement through the use of a pumping system. Criteria for the proper design of forced circulation systems for the improvement of port water quality were defined. Because of the non-linearity of the phenomenon of hydrodynamic circulation, some simulations have produced worse situations. The best improvement in water renewal conditions was found in the face of high economic costs.

\section{ACKNOWLEDGEMENT}

The authors express their gratitude to Dr. Andrea Pedroncini of DHI Group for his technical support.

\section{REFERENCES}

[1] Estacio, F.J. et al., Ecological analysis in a polluted area of Algeciras Bay (southern Spain): External "versus" internal outfalls and environmental implications. Marine Pollution Bulletin, 34, pp. 780-793, 1997.

[2] Mali, M. et al., Are conventional statistical techniques exhaustive for defining metal background concentrations in harbour sediments? A case study: The Coastal Area of Bari (Southeast Italy). Chemosphere, 138, pp. 708-717, 2015.

[3] Mali, M. et al., Identification of hot spots within harbour sediments through a new cumulative hazard index. Case study: Port of Bari, Italy. Ecological Indicators, 60, pp. 548-556, 2016.

[4] Mestres, M., Sierra, J.P., Mosso, C. \& Sànchez-Arcilla, A., Sources of contamination and modelled pollutant trajectories in a Mediterranean harbour (Tarragona, Spain). Marine Pollution Bulletin, 60(6), pp. 898-907, 2010.

[5] Mali, M., Dell'Anna, M.M., Mastrorilli, P., Damiani, L. \& Piccinni, A.F., Assessment and source identification of pollution risk for touristic ports: Heavy metals and polycyclic aromatic hydrocarbons in sediments of 4 marinas of the Apulia region (Italy). Marine Pollution Bulletin, 114(2), pp. 768-777, 2017.

[6] Mali, M., De Serio, F., Dell'Anna, M.M., Mastrorilli, P., Damiani, L. \& Mossa, M., Enhancing the performance of hazard indexes in assessing hot spots of harbour areas by considering hydrodynamic parameters. Ecological Indicators, 73, pp. 38-45, 2017.

[7] EC, Directive 2000/60/EC of the European Parliament and of the Council establishing a framework for Community action in the field of water policy. Official Journal of the European Communities, C513, 2000.

[8] Zakaria, M.P. et al., Distribution of polycyclic aromatic hydrocarbons (PAHs) in rivers and estuaries in Malaysia: a widespread input of petrogenic PAHs. Environmental Science \& Technology, 36(9), pp. 1907-1918, 2002.

[9] De Luca, G. et al., Nature, distribution and origin of polycyclic aromatic hydrocarbons (PAHs) in the sediments of Olbia harbor (northern Sardinia, Italy). Marine Pollution Bulletin, 50(11), pp. 1223-1232, 2005.

[10] De Serio, F., Malcangio, D. \& Mossa, M., Circulation in a Southern Italy coastal basin: Modelling and field measurements. Continental Shelf Research, 27(6), pp. 779-797, 2007. 
[11] Malcangio, D. \& Petrillo, A.F., Modeling of brine outfall at the planning stage of desalination plants. Desalination, 254, pp. 114-125, 2010.

[12] Pietrzak, J., Jakobson, J.B., Burchard, H., Vested, H.J. \& Petersen, O., A three-dimensional hydrostatic model for coastal and ocean modelling using a generalised topography following co-ordinate system. Ocean Modelling, 4(2), pp. 173-205, 2002.

[13] Passenko, J., Lessin, G., Erichsen, A.C. \& Raudsepp, U., Validation of hydrostatic and non-hydrostatic versions of the hydrodynamical model MIKE 3 applied for the Baltic Sea. Estonian Journal of Engineering, 14(3), pp. 255-270, 2008.

[14] Guyondet, T., Koutitonsky, V.G. \& Roy, S., Effects of water renewal estimates on the oyster aquaculture potential of an inshore area. Journal of Marine Systems, 58(2), pp. 35-51, 2005.

[15] Lessin, G. \& Raudsepp, U., Water quality assessment using integrated modeling and monitoring in Narva Bay, Gulf of Finland. Environmental Modelling Assessment, 11, pp. 315-332, 2006.

[16] Ben Meftah, M., Damiani, L., De Serio, F., Mossa, M. \& Petrillo, A.F., Analysis of current circulation in the port of Bari. Geo-Eco-Marina, 17, pp. 5-12, 2011.

[17] Koutitonsky, V.G., Guyondet, T., St-Hillaire, A., Courtenay, S.C. \& Bohgen, A.D., Water renewal estimates for aquaculture developments in the Richibucto estuary, Canada. Estuaries, 27, pp. 839-850, 2004. 